\title{
DISTURBANCES OF OCULOMOTOR FUNCTION ACCOMPANYING EXTRADURAL HAEMORRHAGE
}

BY

\section{S. SUNDERLAND and K. C. BRADLEY}

From the Department of Anatomy and Histology, University of Melbourne, and the Neurosurgical Unit, Alfred Hospital, Melbourne, Australia

That the state of the pupils provides an important clue to lesions developing at the base of the brain has been known for a long time, and there are few accounts in the literature devoted to extradural haemorrhage which do not contain a reference to the diagnostic significance of the pupillary signs associated with this condition. A review of the literature, however, indicates that information is incomplete or contradictory on the following points. (1) The precise time-sequence of the changes in both pupils and the significance which is attached to these : these changes were regarded by earlier writers as of considerable diagnostic significance though they were unaware of the factors responsible for them. In more recent times, however, there has been a tendency to emphasize the final phase of the process, as represented by bilateral dilated fixed pupils, and to neglect the sequence of events which leads up to it. (2) Whether the signs of third nerve involvement are central, nuclear, or peripheral in origin. (3) The mechanism by which oculomotor function is disturbed. (4) Whether or not function is also impaired or lost in the field served by the somatic motor fibres of the oculomotor nerve and if so whether these changes precede, follow, or develop simultaneously with those due to involvement of the pupillo-constrictor component. This introduces the question of the relative susceptibility of the various fibres, somatic, motor, and pupillo-constrictor, to mechanical deformation and whether such differential susceptibility, if it exists, is to be accounted for on the basis that some fibres are physiologically more sensitive or anatomically less well protected. This feature has assumed significance in view of a recent observation (Sunderland and Hughes, 1946) which indicates a relative concentration of the pupillo-constrictor fibres in the upper sector of the oculomotor nerve. (5) In the event of conduction being blocked in all fibres, the rate and order in which different fibres recover following relief from mechanical distortion.
The object of this paper is to report the results of an investigation undertaken to answer these questions. During the course of the enquiry other interesting points have emerged. Incidentally, we are not concerned with disturbances of oculomotor function which immediately follow injuries of the orbital contents or of the third nerve in the form of a tearing or avulsion of its fibres, or of haemorrhage into its nucleus in the mid-brain. The type of disturbance under review concerns secondary involvement of the nerve arising from complications as a result of the injury which lead to the gradual development of signs some time after the accident, often as the patient is becoming increasingly comatose.

\section{Material}

The account of the normal anatomy of the oculomotor nerve is based on the examination of more than 100 cadavers, and the distortion which occurs at the base of the brain following cerebral shift and tentorial herniation has been investigated in nine necropsy specimens, four of which were the result of an extradural haemorrhage. The necropsy material permitted a reconstruction of the events which follow the development of these complications. Observations were also made on nine cases of extradural haemorrhage in which the pupillary changes and eye movements were followed in as great detail as was practicable. In a further 16 cases hospital records were consulted ; in general these were incomplete but some information was provided by each. There is no need to elaborate the difficulties of carrying out repeated observations on a critically injured person and of testing eye movements in the unconscious individual. For these reasons some of our own records are inevitably incomplete.

In four of the patients who died the brain was obtained at necropsy in a state which permitted a study of the manner in which the pupillary signs had been produced. 


\section{Normal Anatomy}

The oculomotor nerve emerges from a sulcus on the medial aspect of the cerebral peduncle and passes forwards and laterally to skirt the lateral margin of the posterior clinoid process. The nerve then passes on to, and courses along, the roof of the cavernous sinus for a short distance before entering the lateral wall of that structure. Between the brain stem and the posterior clinoid process the nerve is crossing the interval bounded by the margin of the tentorial notch laterally, the dorsum sellae anteriorly, and the brain stem posteriorly. This interval will be called the tentorial gap.

As it crosses this space the nerve has certain important vascular and cerebral relations (Figs. 1, 2, 3, and 4). Superior relations are the posterior communicating and posterior cerebral arteries; the latter crosses the nerve on its way laterally. The superior cerebellar artery runs beneath the nerve as it travels laterally to pass beneath the tentorium. A portion of the uncal region of the temporal lobe normally extends inwards over the margin of the tentorium and into the tentorial gap ; in doing so it becomes closely related, supero-laterally, to the third nerve. It should be emphasized that this portion of the temporal lobe is, in the majority of cases, a normal content of the tentorial gap and a customary superior relation of the third nerve.

An earlier investigation has shown that the pupillo-constrictor fibres are concentrated in the upper part of the nerve from the cavernous sinus to the mid-brain (Sunderland and Hughes, 1946). Thus two vessels, the posterior cerebral and the posterior communicating, and a portion of the temporal lobe are intimately related to that aspect of the third nerve in which the pupillo-constrictor fibres are concentrated.

\section{Pathological Anatomy}

As bleeding occurs into the extradural space the subjacent cerebral hemisphere is compressed in a general direction medially. As a result the cerebral tissue, which is normally related to the tentorial gap, is forced downwards through it into the posterior cranial fossa. Though several accounts are available of the manner in which tentorial herniations develop in a variety of supratentorial expanding lesions (Meyer, 1920; Kernohan and Woltman, 1929; Spatz and Stroescu, 1934; Vincent, David, and Thiébaut, 1936 ; van Gehuchten, 1937 ; Jefferson, 1938 ; Schwarz and Rosner, 1941; Evans and Scheinker, 1943; Scheinker, 1945), few of these refer to, or are concerned with, involvement of the third nerve and those that do omit significant details pertaining to the mechanism of this involvement and to the associated disturbances of function. Exceptions are the accounts by Dott (1939) and Reid and Cone (1939).

On the side of the lesion the herniated mass is, in the initial stages, forced on to the upper surface of the third nerve which is crossing the gap beneath it, while the posterior cerebral artery, which is intervening between the two, deforms both and may subsequently be compressed between them (Figs. 5 and 6). The superior portion of the nerve is the first to be affected, and, since the pupillo-constrictor fib-es are concentrated in this region, early changes in the pupil on the affected side would be expected. Further complications develop as the supratentorial pressure increases.

That portion of the uncal region of the temporal pole which is overhanging the tentorial gap on the contralateral side may be forced on to and may compress the subjacent oculomotor nerve. Further development of the herniation on this side is usually prevented, however, because of the manner in which the herniation on the ipsilateral side comes to occupy the tentorial gap (vide infra).

The mid-brain is compressed both to the opposite side and backwards as the herniation on the ipsilateral side increases. The cerebral peduncle on the involved side assumes a more vertical direction than that on the opposite side, which is driven against the free edge of the tentorium (Figs. 7, 8, and 9). As a result of this displacement the ipsilateral third nerve comes to run more acutely laterally, is stretched, and is pulled more firmly into contact with the posterior clinoid process. The nerve on the opposite side, on the other hand, comes to run almost directly forwards and is slackened. This feature is illustrated in Figs. 7, 8, and 9. All the fibres comprising the ipsilateral third nerve are now involved and the deformation is such that the pupillo-constrictor fibres would have ceased to conduct.

As the infratentorial cerebral mass continues to increase in size it ultimately reaches and impinges upon the upper surface of the pons on the same side. The pons is tilted downwards, the descent being facilitated by the elongation of the mid-brain which follows its lateral compression. Two factors which further embarrass conduction in the third nerve are introduced by this movement. (1) Each third nerve is stretched because the site of origin from the medial aspect of the cerebral peduncle descends. (2) The basilar artery, which is tethered to the surface of the pons by numerous, short, transversely directed pontine branches, moves distally with the pons and with it the origin of each posterior cerebral branch. As a result each artery must ascend more 


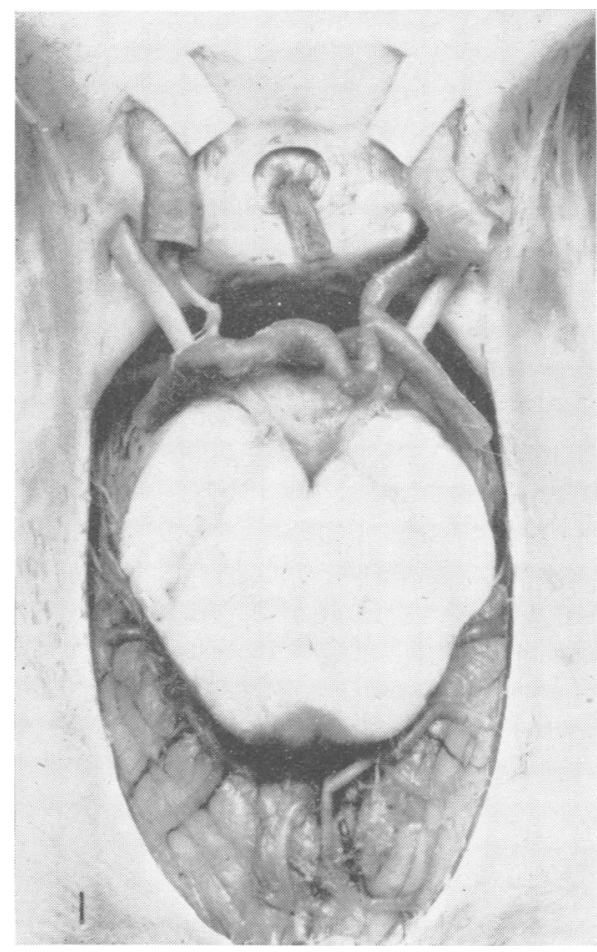

Fig. 1.-The base of the skull, viewed from above, in the region about the pituitary fossa, the cavernous sinus, and the tentorial notch. The manner in which the third nerve crosses the tentorial gap and is related to the posterior cerebral artery, the posterior communicating artery and the roof of the cavernous sinus is shown.

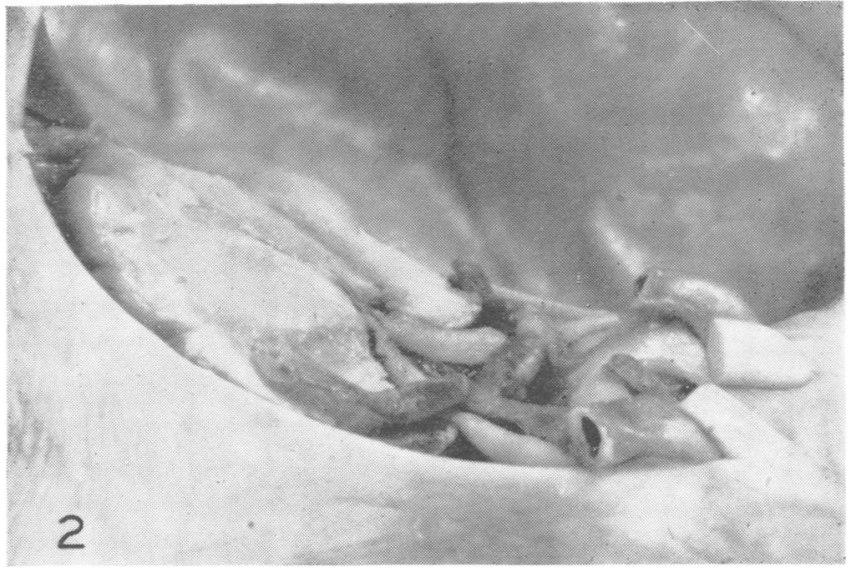

Fig. 2.-The region illustrated in Fig. 1 viewed from the lateral aspect to demonstrate the course of the third nerve across the tentorial gap as it passes between the posterior cerebral and superior cerebellar arteries.

Fig. 4.-Basal aspect of the brain illustrating the boundaries and contents of the interpeduncular fossa. The stump of the third nerve is seen directed outwards and forwardso between the posterior cerebral and superior cerebellas $\omega$ arteries. The posterior communicating artery is show above and medial to the nerve. The indentation made in the temporal lobe by the free margin of the tentorium clearly shown, as well as that portion of the uncus which bulges over the tentorial margin into the tentorial gapo

The third nerve is seen to be a direct inferior relation of the $O$ uncal bulge as it passes forwards and outwards.

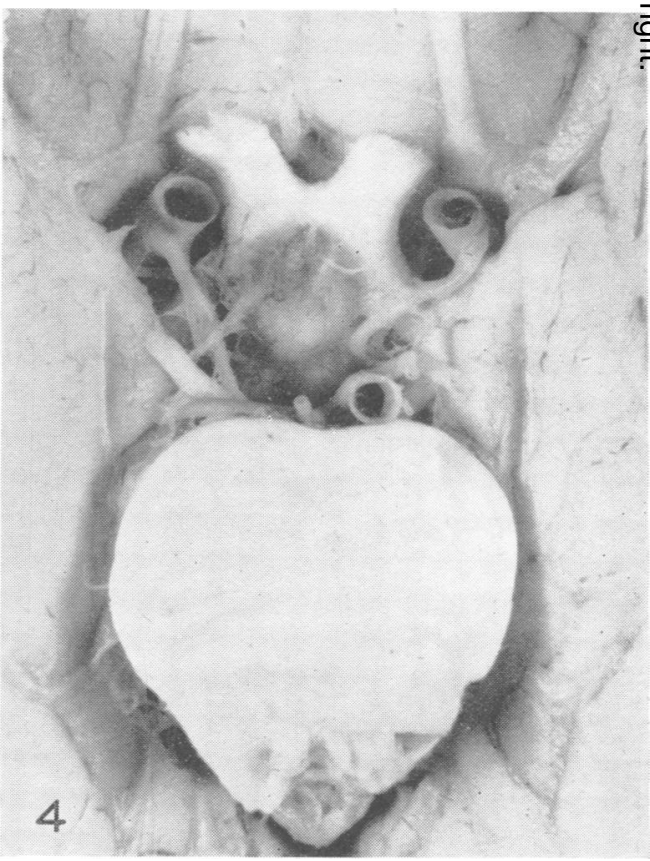

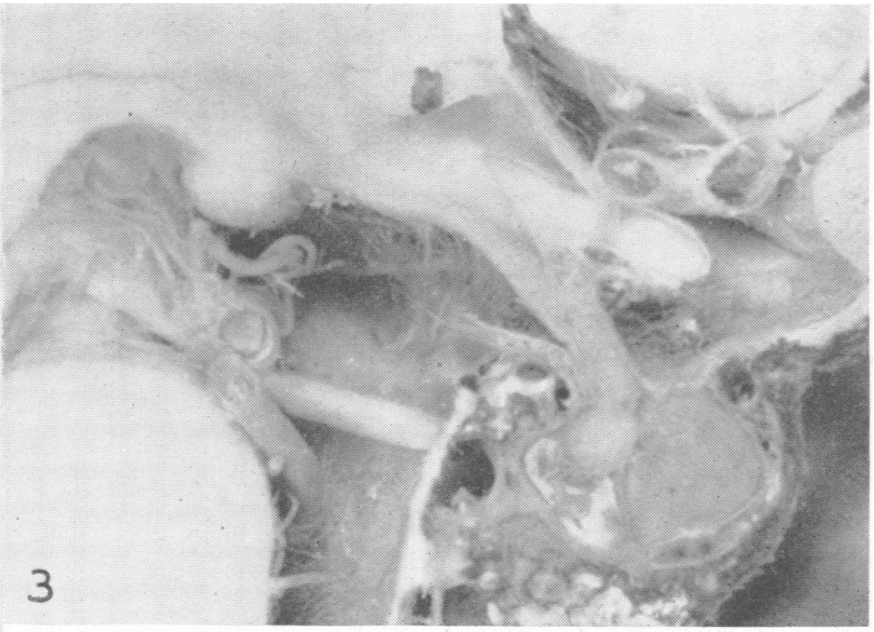

3.-A mid-sagittal section of the base of the brain and the base of the skull illustrating how the third nerve crosses the tentorial gap and the manner in which it is sandwiched between the posterior cerebral and superior cerebellar arteries. 


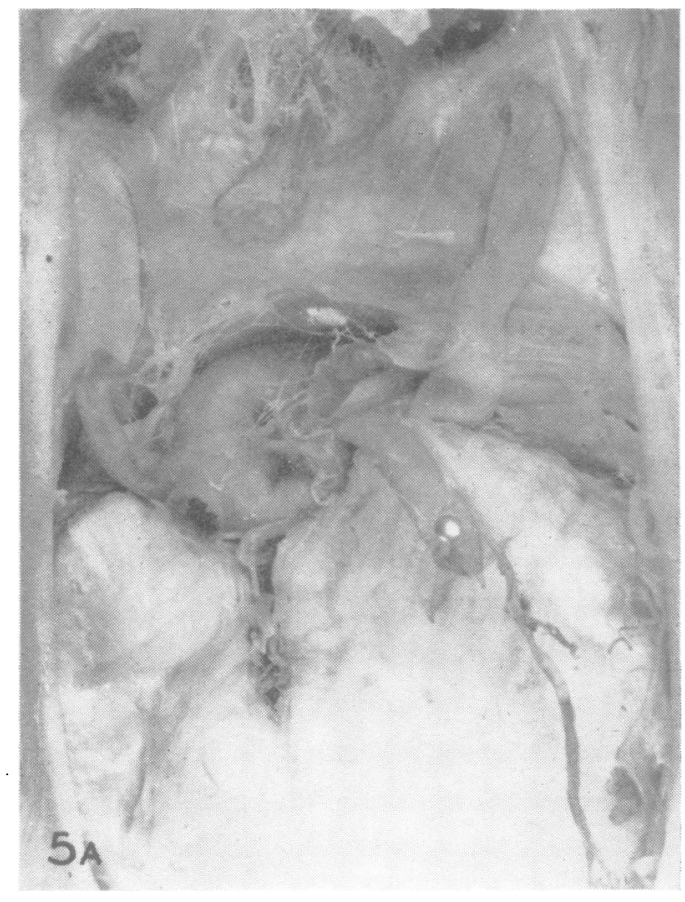

Fig. 5A.-Example of a tentorial herniation on the right side which has forced the posterior cerebral artery into the upper surface of the underlying third nerve. The artery has been reflected in order to expose the impression left on the upper surface of the nerve.

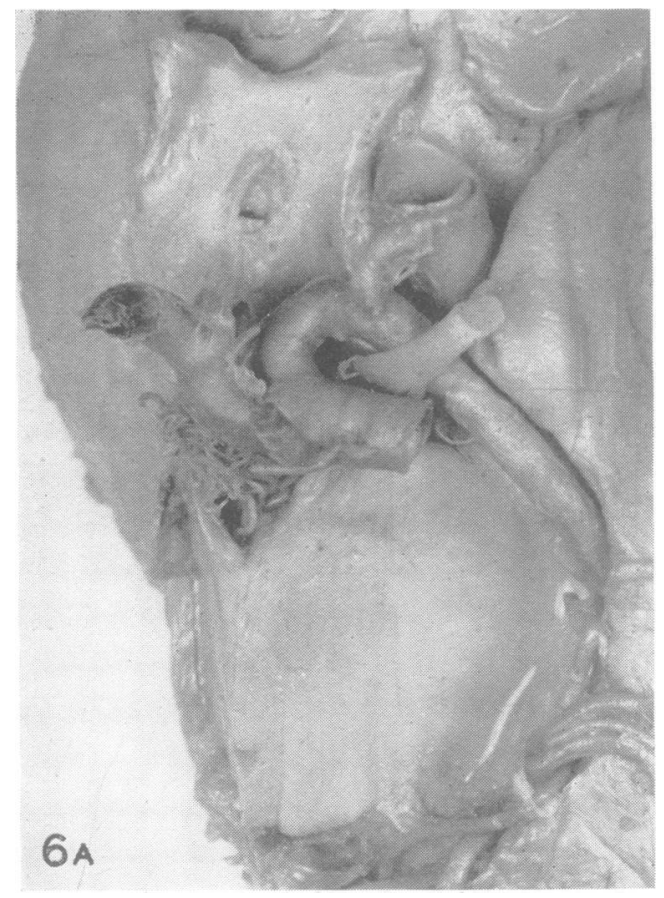

FIG. 6A.-The under surface of the brain in the region of the interpeduncular fossa in a specimen of tentorial herniation which illustrates the manner in which the posterior cerebral artery has deformed the herniated portion of temporal lobe and the third nerve.

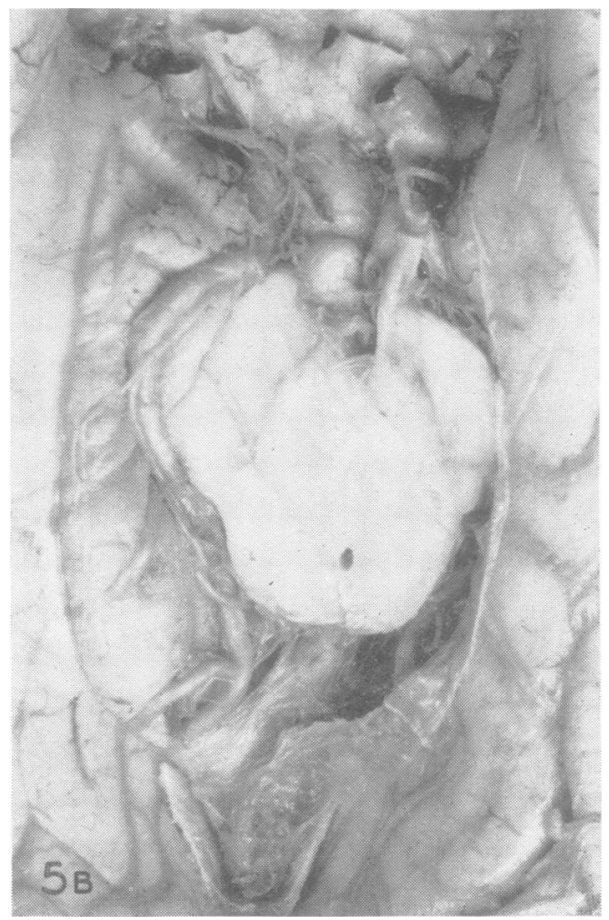

FIG. 5B.-The basal view of the brain corresponding to the arrangement at the base of the skull illustrated in A. The extent of the tentorial herniation on the side of the lesion is shown. On the under surface of the anterior portion of the herniation is shown the deep groove outlined and occupied by the third nerve as the herniated tissue was forced down upon it. The distortion of the opposite cerebral peduncle is well shown in comparison with the arrangement on the side of the herniation.

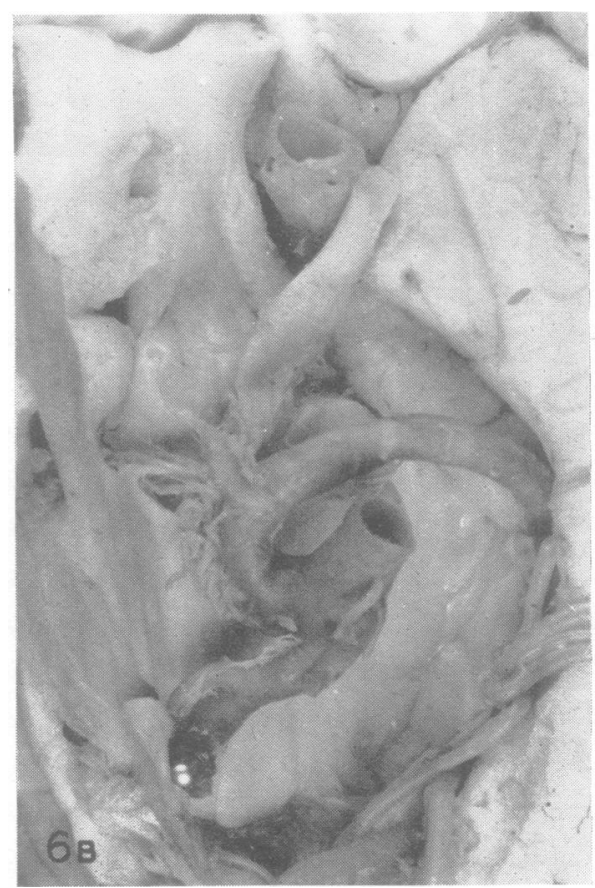

FIG. 6B.-The nerve has been displaced away from the artery to reveal the extent of the deformation. 


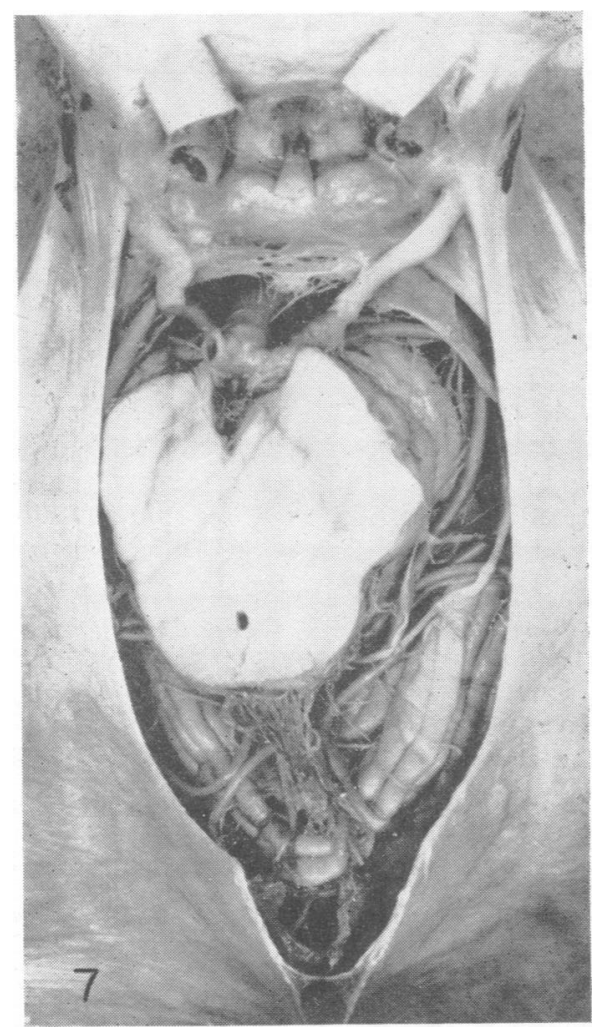

Fig. 7

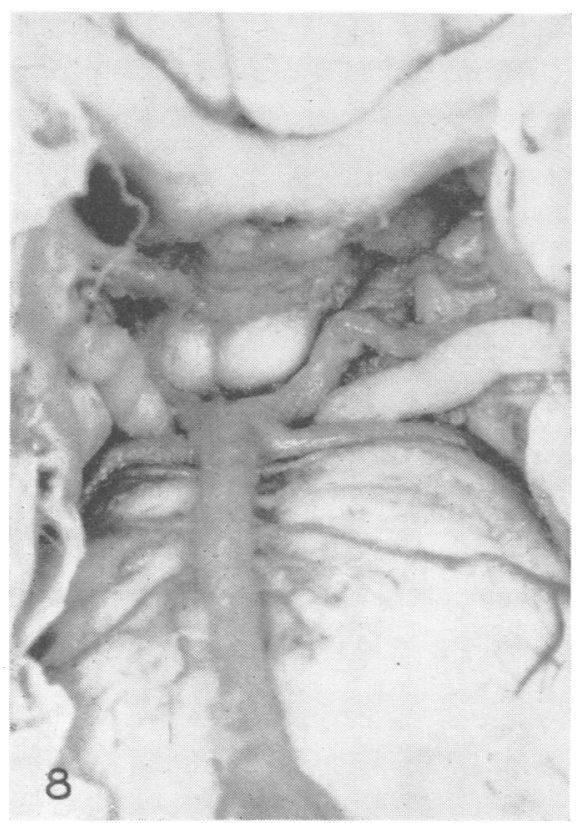

FIG. 8

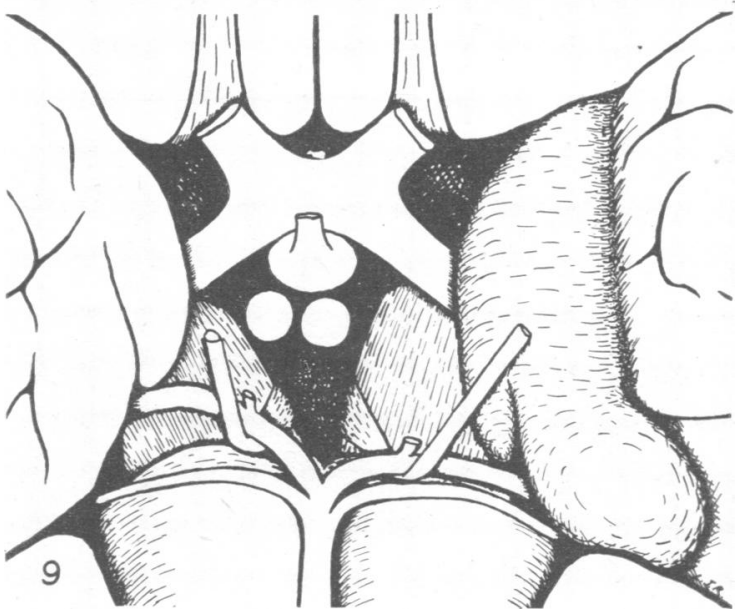

Fig. 9.-The interpeduncular region in a case of extradural haemorrhage with a tentorial herniation. The region has been exposed to illustrate some of the consequences of the herniation : (1) the angulation of each third nerve produced as it first descends to pass beneath the posterior cerebral artery ; (2) the alteration in the course taken by each third nerve as it passes towards the cavernous sinus; (3) the displacement of the ipsilateral cerebral peduncle and interpeduncular structures e.g., the mammillary bodies; (4) the impingement of the herniated cerebral mass on the pons which is deflected downwards, particularly on the ipsilateral side.

acutely in the initial part of its course in order to reach a supratentorial position, and in doing so each is pulled across and kinks the upper surface of the corresponding third nerve which has moved only slightly downwards at its origin. The final arrangement in the necropsy material was one in which the oculomotor nerves passed acutely downwards from their origin to reach the under surface of the corresponding posterior cerebral artery before turning acutely upwards, and then forwards and outwards towards the posterior clinoid process ; the angle of kinking produced in this way varied from $90^{\circ}$ to $100^{\circ}$ (Fig. 9). The compression and angulation of

FIG. 7.-The arrangement of the parts in the region of the hiatus of the tentorium in a case of right-sided tentorial herniation. The brain stem has been deflected to the left and the left cerebral peduncle compressed against the free edge of the tentorium. As a result of this displacement the origin of the right third nerve has moved to the left and the nerve now runs more acutely outwards and forwards. The origin of the left nerve, however, has been displaced so that it is now closer to, and more directly behind, the posterior clinoid process on that side. As a result the nerve is slackened. The stretching of the ipsilateral nerve and the slackening of the contralateral are well shown. (The origin of the left third nerve from the brain stem was unfortunately destroyed during the removal of the brain.)

FIG. 8.-Basal view of the brain in a case of tentorial herniation illustrating the displacement of the interpeduncular structures (e.g. mammillary bodies) to the contralateral side. The difference in the angle of inclination of the two third nerves is clearly shown as is the stretching on the ipsilateral and the slackening on the contralateral side. Also well shown is the manner in which the contralateral third nerve is forced into the angle of divergence of the posterior cerebral and superior cerebellar arteries as a result of the displacement brought about by the herniation. 
the nerve thus produced was particularly marked on the ipsilateral side where the pons and artery were displaced further distally owing to the tilting of the former. It should be noted, however, that the superior aspect of the contralateral third nerve is finally involved as the result of such gross displacement. Furthermore the lateral displacement described above could also be responsible for wedging the contralateral nerve more securely into the angle outlined by the diverging posterior cerebral and superior cerebellar arteries (Fig. 8).

Lastly as the supratentorial pressure increases, the brain stem is compressed and this results first in narrowing of the aqueduct of Sylvius, obstruction of the flow of the cerebrospinal fluid, and a further rise in the supratentorial pressure. A vicious circle is thereby introduced in which the herniation aggravates those conditions which favour and accelerate its development. The second result is compression of the contralateral cerebral peduncle against the firm free edge of the tentorium. In this peduncle are descending the corticospinal fibres which are destined for the ipsilateral side. Involvement of these fibres leads to the appearance of signs of an upper motor neuron lesion on the same side as that on which the haemorrhage is occurring.

As the herniation continues to enlarge, the brain stem is slowly compressed until the aqueduct of Sylvius and the neighbouring vessels are obliterated and the vital functions are embarrassed and ultimately fail.

There may be some departures from this sequence of events but these are of a minor nature.

A study of our pathological material demonstrates that the third nerve is involved where it is slung across the tentorial gap and not where " it crosses the greater wing of the sphenoid bone" as has been described by Reid and Cone (1939). We also do not agree with the statement of Gurdjian (1938) that " the third nerve paralysis is brought about by pressure against the third nerve in its course through the superior orbital fissure ". Furthermore in the post-mortem specimens there was no other cerebral pathology which could have accounted for the disturbances of oculomotor function.

The findings indicate that the order of involvement of the fibres comprising the third nerves is as follows : (1) the superior portion of the ipsilateral nerve in which are concentrated the pupilloconstrictor fibres; (2) the remainder of the ipsilateral nerve and hence its somatic motor fibres; (3) the superior portion of the contralateral nerve and therefore the contralateral pupillo-constrictor fibres; (4) the remainder of the contralateral nerve which represents the somatic component.
In this process the rate of development of the distortion is important but with extradural haemorrhage it usually occurs sufficiently rapidly to lead to the early appearance of signs of impaired conduction in the nerve.

\section{Generalizations Based on Clinical Observations}

The Behaviour of the Pupils.-The pupillary changes appeared early and progressed rapidly to the final phase when both pupils were fully dilated and fixed. Excluding two patients, who pursued a subacute course and failed to develop oculomotor signs, the first change was observed on the ipsilateral side in every case and was evident within seven hours of the injury; in three patients it had appeared within the first hour. Both pupils were fully dilated and fixed approximately two to five hours after the appearance of the pupillary changes, though in one patient this condition was delayed for 12 hours.

An analysis of the data indicates that the pupillary changes developed in the following order :- First, the pupil on the affected side constricted; this phase is apparently very short. In three patients the ipsilateral pupil was constricted when they were first examined three hours, three and a quarter hours, and three hours 35 minutes after the injury and the pupil was dilating when they were next examined 30,20 , and 45 minutes later respectively. In these cases the duration of the constriction before the initial examination could not be determined, but the sequence of events observed in the contralateral pupil confirms the belief that the phase of ipsilateral pupillary constriction is very brief. Thus, unless the patient is examined in the early stages and at very short intervals, the constriction would be missed. This could explain why it was not seen in the other cases and why so many have failed to observe it.

Secondly the pupil on the affected side slowly dilated and ultimately became fixed in full dilatation. The final stage was reached from one to seven and a half hours after the injury except in one case where eight to 13 hours elapsed before full dilatation occurred. Third, changes ultimately appeared in the contralateral pupil but sometimes began before the terminal stage was reached on the ipsilateral side. There was an initial constriction which persisted for the following periods: 10 to 30 minutes; 10 to 55 minutes; approximately 60 minutes; and for less than one hour. This constriction was followed by dilatation so that approximately four and a half to 16 hours after the injury both pupils were fully dilated and fixed. It is emphasized, however, that the data indicate a rapid rather than a slow progression to full dilatation; 
in most cases both pupils were fully dilated and fixed within seven hours. Holman and Scott (1925) have also stressed " the rapidity with which pupillary dilatation may appear on one side and be followed after a brief interval by dilatation on the other side ".

State of the Pupils in Relation to Prognosis. Eleven patients died immediately or shortly after decompression. The state of the pupils immediately preceding decompression and the influence of the latter on the former are listed in Table I. A study of these data indicates that bilateral fully dilated and fixed pupils is an ominous sign, particularly when it has existed for more than $\mathbf{3 0}$ minutes. Two patients with these signs did survive, but in them the condition had existed for less than 15 minutes. This demonstrates the importance of early recognition and treatment. In three of the 11 fatal cases the pupil on the involved side was fully dilated and fixed while the pupil on the contralateral side was not affected. Thus recovery does not necessarily follow decompression at a time when the pupillary changes are confined to one side. The behaviour of the pupils following decompression was a valuable prognostic sign. In the cases terminating fatally decompression had no effect on the state of the pupils except in two patients. In one the pupils had returned to normal 12 hours after operation; death occurred five hours later. A necropsy could not be performed and death may not have been due to the complication which is believed to be responsible for the persistence of the pupillary signs. In the second there was a reduction in size following decompression but no recovery of the reaction to light. A necropsy revealed an unrelieved tentorial herniation.

On the other hand, in the surviving patients there was, with one exception, a rapid recovery of pupillary activity ; in the exceptional case recovery was delayed somewhat (Table II).

Behaviour of the Pupils after a Second Bleeding.In two patients further bleeding occurred after a decompression which had been followed by recovery of the pupillo-constrictor mechanism. In one dilatation of the pupil on the affected side was observed two hours 40 minutes after the first operation ; it had not been present 60 minutes earlier. This pupil was fully dilated and fixed when next observed 30 minutes later at which time the contralateral pupil was enlarging. At this stage the wound was reopened. This resulted in the recovery of the contralateral pupil within a few minutes, but two hours elapsed before both pupils were equal in size and normal in appearance and reaction. In the
TABLE I

STATE OF PUPILS BEFORE AND AFTER DECOMPRESSION FOLLOWED BY DEATH

\begin{tabular}{|c|c|c|}
\hline Patient & $\begin{array}{l}\text { State of Pupils before } \\
\text { Operation }\end{array}$ & State of Pupils after Operation \\
\hline C. D. & $\begin{array}{l}\text { Both fully dilated and } \\
\text { fixed for approxi- } \\
\text { mately } 60 \text { minutes }\end{array}$ & No record \\
\hline C. P. & $\begin{array}{l}\text { Both fully dilated and } \\
\text { fixed for an unspeci- } \\
\text { fied period }\end{array}$ & No record \\
\hline E. K. & $\begin{array}{l}\text { Both fully dilated and } \\
\text { fixed for } 30 \text { minutes }\end{array}$ & Unchanged \\
\hline L. G. & $\begin{array}{l}\text { Both fully dilated and } \\
\text { fixed for } 30 \text { minutes }\end{array}$ & Unchanged \\
\hline H. R. & $\begin{array}{l}\text { Both fully dilated and } \\
\text { fixed for } 50 \text { minutes }\end{array}$ & Unchanged \\
\hline B. I. B. & $\begin{array}{l}\text { Ipsilateral fully dilated } \\
\text { and fixed for six } \\
\text { hours and the contra- } \\
\text { lateral fully dilated } \\
\text { and fixed for } 30 \text { to } \\
60 \text { minutes }\end{array}$ & Unchanged \\
\hline W. M. & $\begin{array}{l}\text { Both fully dilated and } \\
\text { fixed when first seen } \\
\text { four and a half hours } \\
\text { after the injury }\end{array}$ & $\begin{array}{l}\text { One and a half hours after } \\
\text { operation slight reduction in } \\
\text { size of both pupils which were } \\
\text { not reacting to light; eleven } \\
\text { hours after operation pupils } \\
\text { further reduced in diameter } \\
\text { but not reacting; remained } \\
\text { in this state for three and a } \\
\text { half days when both pupils } \\
\text { suddenly dilated, first the } \\
\text { ipsilateral pupil second the } \\
\text { contralateral. Subtemporal } \\
\text { decompression revealed a } \\
\text { swollen brain. Operation } \\
\text { followed by slow reduction } \\
\text { in the size of both pupils } \\
\text { over six to 10 hours. No } \\
\text { reaction to light and the } \\
\text { ipsilateral pupil remained } \\
\text { larger than the contralateral. } \\
\text { No further change and patient } \\
\text { died six days later }\end{array}$ \\
\hline R. C. & $\begin{array}{l}\text { Ipsilateral dilated and } \\
\text { fixed for at least } 60 \\
\text { minutes; contra- } \\
\text { lateral dilating for } \\
30 \text { minutes }\end{array}$ & Unchanged \\
\hline D. B. & $\begin{array}{l}\text { Ipsilateral fully dilated } \\
\text { and fixed }\end{array}$ & $\begin{array}{l}\text { Ipsilateral unchanged ; contra- } \\
\text { lateral fully dilated and fixed } \\
\text { half an hour before death }\end{array}$ \\
\hline J. F. & $\begin{array}{l}\text { Ipsilateral fully dilated } \\
\text { and fixed for } 45 \\
\text { minutes }\end{array}$ & $\begin{array}{l}\text { Pupils had returned to normal } \\
\text { within } 12 \text { hours of decom- } \\
\text { pression; death five hours } \\
\text { later }\end{array}$ \\
\hline G. G. & $\begin{array}{l}\text { Ipsilateral fully dilated } \\
\text { and fixed for at least } \\
90 \text { minutes }\end{array}$ & Unchanged \\
\hline
\end{tabular}

second patient the pupils were equal and reacting two hours after the first decompression. Ninety minutes later the ipsilateral pupil was slightly larger than the contralateral and within 15 minutes it was fully dilated and fixed. A second decompression was performed 40 minutes later when the ipsilateral pupil was fully dilated and fixed and the contralateral was normal and reacting. Within two minutes of evacuating the clot the ipsilateral pupil 
began to react without altering in size. Two hours after the operation both pupils were normal in

TABLE II

STATE OF PUPILS BEFORE AND AFTER DECOMPRESSION FOLLOWED BY RECOVERY

\begin{tabular}{|c|c|c|}
\hline Patient & $\begin{array}{l}\text { State of Pupils before } \\
\text { Operation }\end{array}$ & State of Pupils after Operation \\
\hline A. M. & $\begin{array}{l}\text { Both fully dilated and } \\
\text { fixed for } 15 \text { minutes } \\
\text { (ipsilateral for } 0 \text { to } \\
\text { three and three quar- } \\
\text { ter hours, contra- } \\
\text { lateral for } 15 \text { minutes) }\end{array}$ & $\begin{array}{l}\text { Both equal and reacting when } \\
\text { skull was being closed }\end{array}$ \\
\hline W. H. & $\begin{array}{l}\text { Both fully dilated and } \\
\text { fixed for a few min- } \\
\text { utes (ipsilateral for } \\
\text { one and a quarter to } \\
\text { two hours, contra- } \\
\text { lateral for a few } \\
\text { minutes) }\end{array}$ & $\begin{array}{l}\text { Both moderately dilated and } \\
\text { reacting to light five to } 13 \\
\text { minutes after decompression. } \\
\text { Pupillo-constrictor fibres re- } \\
\text { covered gradually in next } \\
\text { six hours, ipsilateral lagging } \\
\text { slightly behind contralateral }\end{array}$ \\
\hline L. F. & $\begin{array}{l}\text { Ipsilateral fully dilated } \\
\text { and fixed for } 15 \\
\text { minutes; contra- } \\
\text { lateral smaller and } \\
\text { reacting }\end{array}$ & $\begin{array}{l}\text { Within } 10 \text { minutes both equal } \\
\text { in size, moderately dilated } \\
\text { and reacting to light ; } 70 \\
\text { minutes later normal in their } \\
\text { appearance and reactions ; } \\
2 \text { hours } 40 \text { minutes after } \\
\text { operation, slight dilatation of } \\
\text { the ipsilateral pupil ; } 30 \\
\text { minutes later, ipsilateral pupil } \\
\text { fully dilated and fixed and the } \\
\text { contralateral dilating with } \\
\text { slight reaction to light. Imme- } \\
\text { diate decompression and with- } \\
\text { in minutes contralateral pupil } \\
\text { became reduced. Two hours } \\
\text { after second operation both } \\
\text { pupils equal in size and normal } \\
\text { in appearance and reaction }\end{array}$ \\
\hline A. C. & $\begin{array}{l}\text { Ipsilateral fully dilated } \\
\text { and fixed for at least } \\
\text { two and a half hours } \\
\text { contralateral normal }\end{array}$ & $\begin{array}{l}\text { Ipsilateral showed some recovery } \\
\text { two hours later but still larger } \\
\text { than contralateral } 14 \text { hours } \\
\text { after operation }\end{array}$ \\
\hline G. H. & $\begin{array}{l}\text { Ipsilateral almost fuily } \\
\text { dilated and fixed }\end{array}$ & No record \\
\hline T. D. & $\begin{array}{l}\text { Ipsilateral dilated for } \\
\text { two and a half hours } \\
\text { and fixed for approxi- } \\
\text { mately } 30 \text { minutes ; } \\
\text { contralateral normal } \\
\text { and reacting }\end{array}$ & $\begin{array}{l}\text { Both normal, equal in size and } \\
\text { reacting two hours after opera- } \\
\text { tion; three and a half hours } \\
\text { after operation, ipsilateral } \\
\text { larger than contralateral with } \\
\text { both reasting; } 15 \text { minutes } \\
\text { later, ipsilateral dilated and } \\
\text { fixed and contralateral small } \\
\text { and reacting; } 40 \text { minutes } \\
\text { later second decompression, } \\
\text { when ipsilateral pupil dilated } \\
\text { and fixed and contralateral } \\
\text { constricted and reacting. } \\
\text { Clot evacuated : within two } \\
\text { minutes ipsilateral pupil began } \\
\text { to react without altering in } \\
\text { size; } 80 \text { minutes later both } \\
\text { pupils reacting to light with } \\
\text { ipsilateral slightly dilated ; } \\
\text { two hours after operation both } \\
\text { pupils normal in size and } \\
\text { reacting to light }\end{array}$ \\
\hline M. K. & $\begin{array}{l}\text { Ipsilateral fully dilated } \\
\text { and fixed; contra- } \\
\text { lateral not fully di- } \\
\text { lated but fixed for } \\
20 \text { to } 90 \text { minutes }\end{array}$ & $\begin{array}{l}\text { One hour after evacuation of } \\
\text { clot both pupils reduced in } \\
\text { size, ipsilateral to two-thirds } \\
\text { its dilated size and contra- } \\
\text { lateral normal and reacting } \\
\text { sluggishly; 11 hours after } \\
\text { operation both pupils almost } \\
\text { equal in size (ipsilateral } \\
\text { slightly larger than contra- } \\
\text { lateral); seven hours later } \\
\text { both pupils equal in size and } \\
\text { reacting to light }\end{array}$ \\
\hline
\end{tabular}

every respect. Thus the conditions and consequences of the second bleeding were almost identical in the two patients.

The rapidity of the recurrence of the pupillary signs in these patients was presumably due to some residual defect in the pupillo-constrictor fibres following the original decompression which rendered them more vulnerable to a second deformation. Such an explanation is supported by experimental evidence that it is easier to block conduction in peripheral nerves a short time after these have recovered from a compression block.

The Behaviour of the Extraocular Muscles.Independent ocular movements could not be tested in the unconscious individual but observations on the size of the palpebral fissure when the eyes were open and the range of involuntary ocular movements indicated, in the cases investigated, that oculomotor function was affected on the ipsilateral side but not on the contralateral. This ipsilateral disturbance was confirmed when voluntary eye movements could be tested. The findings also indicate early involvement of the somatic component of the nerve. Signs of extraocular involvement, however, persisted for long periods after decompression. The pattern of recovery in five patients was as follows. The medial rectus began to function 29 hours after operation. Six hours later eye movements were full in range but there was a ptosis of the upper lid which did not clear until a further $\mathbf{4 0}$ to 60 hours had elapsed. Eye movements, with the exception of downward gaze, were well performed 22 hours after operation. Twenty-three hours later the upper lid was still ptosed while downward gaze, though full in range, was still weak. Eye movements were fully restored three and a half days after operation; the ptosis was still present the following day but could not be detected when the patient was next examined 19 days later. The somatic fibres were not functioning six days after decompression. Twelve days later there was some recovery of the superior and inferior recti but none in the medial. Seventeen days after operation function was good except for a residual ptosis. Recovery first appeared in the inferior rectus and was well advanced at 36 hours at which time function reappeared in the medial rectus. Four days later both were functioning normally, recovery having advanced more rapidly in the inferior than in the medial. On the other hand elevation of the eye and eyelid did not reappear until four and a half days later and a residual paresis was still evident a further 10 days later. The medial rectus began to function at two and a half days and was 
functioning normally 24 hours later. Recovery in the remaining muscles was delayed for a further three days.

These observations indicate that recovery of the levator palpebrae superioris was delayed in comparison with the recti where the order of recovery varied but favoured the medial and inferior as opposed to the superior.

McKenzie (1938) reported a " varying degree of loss of movement of the eyeball " associated with the pupillary changes accompanying extradural haemorrhage, while Schwarz and Rosner (1941) refer, in passing, to "imbalances in extraocular muscles" associated with tentorial herniations complicating supratentorial tumours. In each case details were not provided. Reid and Cone (1939) have also described involvement of the extraocular muscles but it is not clear from their account whether the pupillary fibres succumbed first ; their data, however, suggest that recovery in the extraocular field was delayed in comparison.

Relative Susceptibility of the Pupillary and Somatic Components in the Oculomotor System.We are unable to say whether the pupillo-constrictor fibres on the ipsilateral side fail before, at the same time, or later than the somatic fibres because when the patients were first examined signs of involvement of both were usually present. However, we are under the impression that the pupilloconstrictor component failed more rapidly and there is no doubt that this system was paralysed on the contralateral side when no disturbance could be detected in the corresponding somatic motor field. In those patients who survived the pupillo-constrictor fibres recovered rapidly, in some cases within a few minutes of the decompression, whereas the recovery of their somatic associates was delayed, for days in the case of the recti muscles and for weeks in the case of the levator palpebrae superioris, although in one patient the recovery of the recti was unduly delayed.

The general conclusion is that the pupilloconstrictor fibres are more susceptible to deformation, or to an associated impairment of their blood supply, than their somatic associates, and that following decompression they recover more rapidly. Furthermore there also appeared to be a relative susceptibility among the somatic fibres in that in some recovery was delayed in comparison with that in others. Whether they failed in any particular order could not be determined.

The Mechanism Responsible for the Pupillary Changes

Any explanation advanced to account for the occurrence of the pupillary changes associated with extradural haemorrhage must also explain the sequence of these changes, their bilateral incidence, their early appearance following the injury, and their prompt recovery on decompression, the involvement of somatic fibres on one side but not on the other, and why the pupils sometimes fail to recover on decompression, and why this is such an ominous sign.

As it develops, the hernia presses first on the upper surface of the third nerve on the same side where it is slung across the tentorial gap. Irritation of the subjacent fibres leads to constriction of the pupil because the pupillo-constrictor fibres are concentrated in the affected sector of the nerve. This phase, however, is usually short. Further bleeding leads to an enlargement of the herniation, further displacement of the parts, and further deformation of the nerve As a result conduction gradually fails in the pupillary fibres until paralysis is complete when the pupil will fully dilate and no longer react. While this is occurring the somatic fibres feel the effects of the compressing force and signs of impaired function appear in the extraocular muscles.

The appearance of signs on the opposite side indicates that the effects of the hernia are now being felt on that side. It has been shown that the hernia, as it enlarges, not only forces the brain stem to the opposite side, thereby driving the opposite cerebral peduncle against the tentorial edge, but that it impinges on the upper surface of the pons on the same side and forces that structure downwards. This leads to the descent of the basilar artery, and with it the origin of the posterior cerebral arteries. As a result each posterior cerebral artery is pulled into the upper surface of the nerve which is running beneath it. On the contralateral side this leads to irritation and later paralysis of the subjacent pupilloconstrictor fibres, and therefore to constriction followed by dilatation of the pupil. The somatic fibres in the contralateral third nerve escape because the mechanism responsible for deforming the nerve acts, initially, on its upper surface. If, however, the angular pull of the artery persisted the somatic fibres would ultimately be involved but before this occurred both pupils would be fully dilated and fixed and the somatic fibres on the ipsilateral side would have failed. This, however, is a condition which should be anticipated by the surgeon and prevented by surgery.

Following decompression and the rapid reduction of the herniation, the parts are relieved in the reverse order in which they were involved. The contralateral third nerve recovers first. On the affected side the pupillo-constrictor fibres recover 
more rapidly than their somatic associates, presumably because the effects of compression on them are less lasting.

\section{The Relative Susceptibility of the Different Fibres To Mechanical Deformation}

The early signs of a pupillo-constrictor involvement on the same side followed by the occurrence of similar signs on the opposite side in the absence of extraocular disturbances suggests that the pupilloconstrictor fibres are more susceptible to mechanical deformation than are the somatic motor fibres. Is this due to the fact that the former are anatomically more exposed or to the fact that they are physiologically more sensitive? The former explanation appears to be the more acceptable. The pupillo-constrictor fibres are concentrated in the upper part of the nerve and this is the first part to feel the effects of the deformation. Furthermore, if they were physiologically more sensitive to deformation it would be expected that, on release, they would recover more slowly. On the contrary, the pupillo-constrictor fibres recover rapidly whereas recovery in their somatic associates is long delayed.

It is believed that the fine fibres in peripheral nerves are less vulnerable to compression than the larger fibres. The findings of this investigation, however, do not conflict with this. The reason why the fine fibres in the oculomotor nerve fail so early is because they are anatomically more exposed. The findings also emphasize that in any consideration of relative susceptibility of nerve fibres to mechanical deformation anatomical features cannot be neglected.

\section{Other Possible Mechanisms Responsible for the Pupillary Changes}

In the preceding sections reasons have been given for attributing the oculomotor changes to involvement of the trunk of the nerve where it is slung across the tentorial gap. It remains to be considered whether the disturbances could be the result of changes initiated at central levels. Cairns (1929) inclined to the view that the pupillary dilatation results from cortical injury or disturbances of fibre tracts of the affected cerebral hemisphere. In the patients investigated by us the distribution of the clot, the absence of a cortical lesion in the cases examined at necropsy, and the pattern of the pupillary changes, particularly the reaction on the contralateral side, excluded a cortical origin for the disturbances.

Whether involvement of nuclear centres in the mid-brain is a contributing factor also requires consideration. However, the manner in which the tentorial herniation develops, the early appearance of pupillary signs confined to the ipsilateral side when mid-brain compression must be negligible, and the absence of somatic motor effects on the opposite side when the corresponding pupil is fully dilated do not favour such an explanation. It might be argued that the pupillo-constrictor centre in the third nerve nucleus is more sensitive to deformation, or ischaemia secondarily induced, than are the somatic components. However the nuclei (right and left) are so close together that it would be difficult to account for the progression of oculomotor signs on the basis of embarrassment of the third nerve nuclei. A nuclear origin for the disturbance has also been excluded by Reid and Cone (1939). This conclusion is consistent with the findings of Magoun, Atlas, Hare, and Ranson (1936) and of Crouch (1936) on the pupillary light reflex, while Bing (1939) describes the extraocular mechanism as suffering first in lesions of the mid-brain.

The herniation if unrelieved may proceed to impaction, and decompression is then without effect. Pressure on the nerves is unrelieved, the pupillary signs persist, and as the herniation continues to enlarge the brain stem is still further compressed, the vital functions are embarrassed ando ultimately fail.

\section{Cases of Extradural Haemorrhage not Associated with Impairment of Oculomotor Function}

It is not to be concluded from this discussion that signs of impaired oculomotor function develop in all cases of extradural haemorrhage. Cases in which they fail to appear and in which the nature and site of the lesion are revealed by other signs are of course well known. There were two such cases in the series studied by us ; these were successfully treated by operation 53 hours and 12 days after the injury. Why the oculomotor mechanisms should be involved in some patients and not in others remains to be explained. The size of the clot alone is not necessarily a contributing factor. Thus in the case in which the diagnosis was not apparent for 53 hours the clot was as large or larger than that present in acute cases where pupillary signs appeared early. Individual variations in the rate of bleeding, in the development of a concomitant cerebral oedema and the extent to which this causes swelling of the brain, and in the arrangements of the parts at the tentorial notch are probably among the contributing factors. Nerves are more tolerant to slow than to rapid deformation. Again in some individuals the brain stem fits so snugly through the tentorial notch that little or no room is 
available for the development of a hernia while in others, and these represent a majority, there is ample room.

\section{The Significance of the Pupillary Changes}

The appearance of pupillary signs following extradural haemorrhage is an indication that a highly dangerous state of affairs in the form of a tentorial herniation is developing.

The following points are emphasized in connexion with this complication.

The pupillary changes appear early and progress rapidly so that within approximately 12 hours of the injury both pupils will be fully dilated and fixed.

The pupillary signs appear first on the side of the lesion in the form of an initial constriction which is rapidly followed by dilatation. On the other hand, the contralateral pupil is not affected until the signs are well advanced on the ipsilateral side. We agree with Cock (1842), Hutchinson (1867-8, 1875-8), Jacobson (1886), Butler (1923), Holman and Scott (1925), Menninger (1927), Cairns (1929), Rand (1929), Blum (1931), Schörcher (1937), McKenzie (1938), and Woodhall, Devine, and Hart (1941) that a dilated fixed pupil is one of the most constant and reliable localizing signs.

Difficulty in localization arises when both pupils are fully dilated and fixed. At this stage, however, help may be obtained from a study of the involuntary ocular movements. The eye on the affected side is stationary whereas that on the opposite side is still roving because the somatic motor fibres on that side are the last to be involved and are only affected in the terminal stages.

The pattern of pupillary change provides a delicate indicator of the progress and extent of the herniation. The importance of the sequence of changes leading to fixed dilated pupils was recognized by the older writers, though they were unaware of the causative factors operating inside the cranium. In recent literature, however, there is a tendency to concentrate on the fixed dilated pupils and to neglect the sequence of events leading up to it. This is dangerous, for there is good reason for believing that by the time both pupils are fully dilated and fixed the tentorial complication is entering its terminal phases. Irreducible impaction is occurring and temporal decompression alone may then fail to correct the complication. The gravity of these extreme pupillary changes should be stressed. The findings of this enquiry suggest that the existence of fixed, dilated pupils for more than half an hour precludes recovery.

If the decompression is effective the pupilloconstrictor fibres recover rapidly. The pupils begin to contract and react within a few minutes of. decompression.

Persistence of pupillary dilatation and the failure of the pupil to react to light after decompression is an ominous sign. An examination of the postmortem material suggests that decompression in these cases has failed to relieve the herniation, probably because it was too long delayed. As a result the pressure on the nerves is unrelieved while obstruction of the aqueduct of Sylvius leads to a further rise in the supratentorial pressure which aggravates the herniation and ultimately leads to death.

The maximum time between paralysis of the pupillo-constrictor mechanism on both sides and decompression which is consistent with survival could not be ascertained but from the limited data at our disposal it appears to be very short (probably somewhere between three and 30 minutes). This emphasizes the importance of recognizing the herniation in the early stages of its development. In this connexion the behaviour of the pupils can be accepted as a delicate indicator of the changes. occurring at the base of the brain.

It is obvious that a larger series of cases will need to be investigated before a critical point can be fixed after which decompression is no longer of avail. In any event individual variations can be expected since the rate of bleeding will vary from patient to patient. Our intention, however, is to emphasize the gravity of the ipsilateral dilated and fixed pupil and to stress that the urgency of surgery is to be measured in minutes rather than in hours.

The rapidity with which the pupillary changes develop and the significance attached to them makes accurate and repeated observations imperative until an extradural haemorrhage can be safely excluded.

Tentorial herniations develop as the result of a wide variety of expanding supratentorial lesions of which extradural haemorrhage is only one. Whether or not pupillary signs appear, depends on the rate at which the herniated mass increases in size and the nerve is distorted. Thus the herniation may develop so slowly that the nerve has time to accommodate itself to the changed conditions and no disturbance of conduction results until the condition is well established. On the other hand, pupillary changes appear early when the hernia develops rapidly, as in extradural haemorrhage which forms a semi-solid, space-occupying plaque. The rate of development of the pupillary signs is presumably influenced by the rate at which bleeding occurs in which individual variations are to be expected. 


\section{Summary}

The disturbances of oculomotor function accompanying extradural haemorrhage have been investigated.

A study of pathological material demonstrates that (1) the disturbances of oculomotor function are due to deformation of the third nerve produced by the development of a tentorial herniation and the consequent displacement and distortion of the mid-brain, and (2) the site of the involvement is the trunk of the nerve where it is slung across the interval, the "tentorial gap", bounded by the margin of the tentorial notch laterally, the dorsum sellae anteriorly, and the brain stem posteriorly.

The manner in which the third nerves are involved, leading to the development of signs in the oculomotor field, is detailed.

Attention is directed to the pattern of pupillary change and to its diagnostic and prognostic significance. The behaviour of the pupils provides a delicate indicator of the changes occurring at the base of the brain.

\section{REFERENCES}

Bing, R. (1939). Textbook of Nervous Diseases. Translated and enlarged by Webb Haymaker, p. 66. London.

Blum, K. (1931). Dtsch. Z. Nervenheilk., 121, 29 !

Butler, E. (1923). Calif. State J. Med., 21, 295.

Cairns, H. (1929). Trans. opthhal. Soc. U.K., 49, 314.

Cock, E. (1842). Guy's Hosp. Rep., 7, 157.

Crouch, R. L. (1936). J. comp. Neurol., 64, 365.

Dott, N. M. (1939). Thomson and Miles' Manual of Surgerv, 9th ed., Chapter 23. London.

Evans, J. P., and Scheinker, I. M. (1943). Arch. Neurol. Psychiat. Chicago, 50, 258.

Gehuchten, P. van (1937). Encéphale, 32 (2), 113.

Gurdjian, E. S. (1938). Amer. J. Surg., 40, 596.

Holman, E., and Scott, W. M.J. (1925). I, Amer. med. Ass, $84,1329$.

Hutchinson, J. (1867-8). London Hosp. Rep., 4, 10. 1875-88). Illustrations of Clinical Surgery, vol. 2, p. 63. London and Philadelphia.

Jacobson, W. H. A. (1886). Guy's Hosp. Rep., 43, 147.

Jefferson, G. (1938). Arch. Neurol. Psvchiat., Chicago, 40, 857.

Kernohan, J. W., and Woltman, H. W. (1929). Ibid., 21, 274.

McKenzie, K. G. (1938). Brit. J. Surg., 26, 346.

Magoun, H. W., Atlas, D., Hare, W. K., and Ranson, S. W. (1936). Brain, 59, 234.

Menninger, W.C. (1927). J. nerv. ment. Dis., 65, 553.

Meyer, A.'(1920). Arch. Neurol. Psychiat.. Chicaso, 4, 387.

Rand, C. W. (1929). Arch. Surg., 18, 1176.

Reid, W. L., and Cone, W. V. (1939). J. Amer. med. Ass., 112, 2030.

Scheinker, I. M. (1945). Arch. Neurol. Psvchiat., Chicago, 53, 289.

Schörcher, F. (1937). Dtsch. Z. Chir., 248, 420.

Schwarz, G. A., and Rosner, A. A. (1941). Arch. Neurol. Psychiat., Chicago, 46, 297.

Spatz, H., and Stroescu, G. J. (1934). Nervenarzt, 7, 425.

Sunderland, S., and Hughes, E. S. R. (1946). Brain, 69, 301

Vincent, C., David, M., and Thiébaut, F. (1936). Rev. Neurol., Paris, 65, 536.

Woodhall, B., Devine, J. W., and Hart, D. (1941). Surg. Gines. Obstet., 72, 391 .

\section{THE NOVEMBER (1952) ISSUE}

The November (1952) issue contains the following papers :-

The Electrogram in Myopathy : Analysis with the Audio-frequency Spectrometer. By John N. Walton.

Thoracic Intervertebral Disc Prolapse with Spinal Cord Compression. By Valentine Logue.

Studies of Ischaemic and Post-ischaemic Paraesthesiae in Normal Subjects and in Sciatica. By John Marshall.

Three Cases of Achondroplasia with Neurological Complications. By John D. Spillane.

A Sex-linked Variant of Gargoylism. By Guy Millman and J. W. Whittick.

Electroencephalographic Studies in Cerebral Angioma. By D. P. Rosenberg.

Disorders of Perception and Performance in a Case of Right-sided Cerebral Thrombosis. By R. W. Gilliatt ${ }^{T}$ and R. T. C. Pratt.

Some Mechanisms of Tactile Localization Revealed by a Study of Leucotomized Patients. By Alick Elithorn, Malcolm F. Piercy, and Margaret A. Crosskey.

A number of copies are still available and may be obtained from the Publishing Manager, British Medical Association, Tavistock Square, W.C.1, price 12s. $6 \mathrm{~d}$. 